23

\title{
Сравнительный анализ спектров люминесценции алмазов
}

\author{
( С.И. Зиенко, Д.С. Слабковский \\ Филиал ФГБОУ ВО НИУ „МЭИ“, \\ 214013 Смоленск, Россия \\ e-mail: stanislav-zienko@rambler.ru
}

Поступила в редакцию 06.12.2018 г.

В окончательной редакции 23.04.2019 г.

Принята к публикации 16.05.2019 г.

\begin{abstract}
Для выявления признаков, отличающих природные алмазы от искусственных, выполнен сравнительный анализ спектров люминесценции по добротности, величине центра тяжести, показателю широкополосности, а также энергетических потерь в кристаллической решетке алмаза в режимах омической и диэлектрической релаксации люминесценции. Обнаружено явление резонансной люминесценции в алмазе в фемтосекундном диапазоне времени. Установлено, что природные и искусственные алмазы заметно различаются по частоте релаксации и энергии резонансного излучения.
\end{abstract}

Ключевые слова: природные и искусственные алмазы, центр тяжести спектра люминесценции, частота релаксации.

DOI: $10.21883 /$ OS.2019.09.48210.354-18

\section{Введение}

В настоящее время для изготовления бриллиантов используют алмазы как природного, так и искусственного происхождения. Поэтому проблема определения их происхождения весьма актуальна. Задача идентификации состоит в определении разновидности алмаза, является ли он камнем - природным, синтетическим или облагороженным.

Алмазы люминесцируют не только в свете ультрафиолетовой лампы, но и при облучении лазерным светом разных длин волн. Спектры люминесценция позволяет выявить центры окраски в алмазах. Эти центры, которые являются индикаторами наличия или отсутствия облагораживания, облучения быстрыми частицами или НРНТобработки (HTHP - High Temperature - High Pressures: один из самых распространенных методов модификации цвета бриллианта).

Установка для съемки спектров люминесценции обычно совмещается в одном приборе с рамановским спектрометром. Образец при измерении спектров люминесценции помещается в кварцевую кювету-приставку с жидким азотом для улучшения спектрального разрешения [1-3].

В настоящей работе представлен новый подход к определению происхождения ограненных алмазов (бриллиантов). Для этого используется фононное крыло спектра люминесценции алмаза при комнатной температуpe $[4,5]$.

Цель работы заключается в сравнительном анализе спектров люминесценции алмазов различного происхождения при комнатной температуре по добротности, величине центра тяжести, показателю широкополосности, а также энергетических потерь в кристаллической решетке в режимах омической и диэлектрической релаксации.
Цель работы - в выявлении признаков, отличающих природные алмазы от алмазов, изготовленных в лаборатории.

Эти вопросы в литературе практически не рассматривались.

В эксперименте исследовали объемное вторичное излучение (люминесценцию и комбинационное рассеяние света (КРС)). Для возбуждения вторичного излучения алмаза использовали лазер с длиной волны $532 \mathrm{~nm}$ [6-8]. Спектры люминесценции и КРС регистрировали с помощью спектрометра-флуориметра РАОС-4 [9-11]. Измерения проводили при комнатной температуре в диапазоне длин волн 530-800 nm. Для получения спектров люминесценции из массива экспериментальных данных удаляли две-три точки в окрестности пика КРС (573 nm). Анализ данных осуществляли по шкале энергии $E=1240 / \lambda$, где $\lambda$ измеряется в нанометрах и $E$ в электронвольтах.

Измеренные спектры проходили стандартную процедуру фурье-фильтрации с целью удаления высокочастотных помех и шумов, удаления постоянной составляющей и нормирование огибающей контура по амплитуде, равной единице. Спектр люминесценции состоит из фононного крыла и несет информацию об общем состоянии решетки алмаза.

\section{Основные характеристики спектров люминесценции в частотной области}

Фононное крыло люминесценции одного из образцов бриллиантов с фантазийной окраской представлено на рис. 1, $a$ [10]. Сверху по оси абсцисс показана шкала энергии, снизу - шкала частот. Последнюю получали путем вычитания из шкалы энергии постоянной coставляющей $E_{0}=1.55 \mathrm{eV}$. При этом частота локальных 


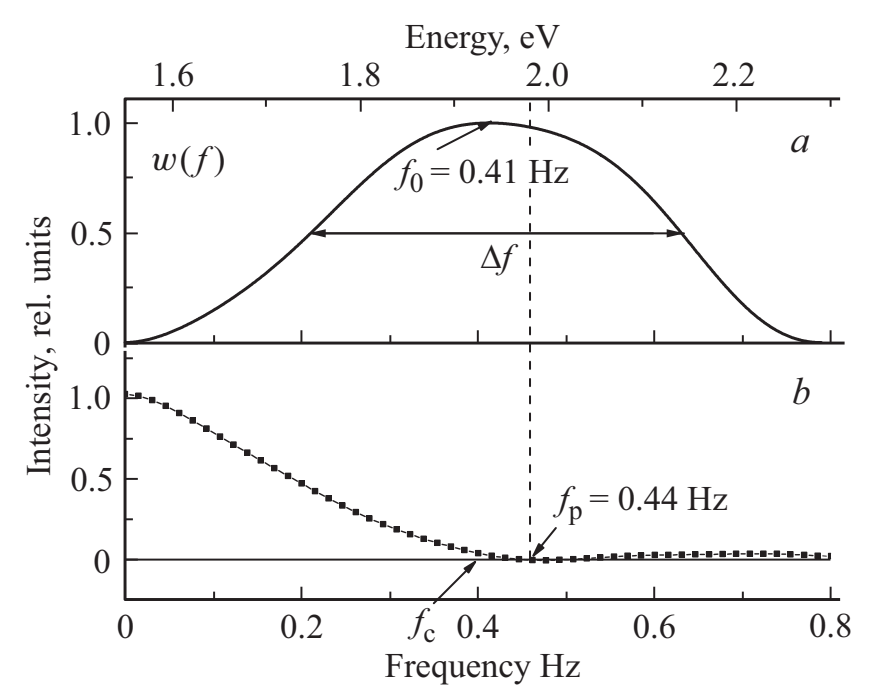

Рис. 1. Фононное крыло люминесценции бриллианта $W(f)$ (П-65, фантазийный, желтый/4, 0.55 кар.) (a); вещественная частотная характеристика $(b), T=300 \mathrm{~K}$.

колебаний $v_{\text {local }}=\left(h v-E_{0}\right) / h$. Для упрощения анализа постоянную Планка $h$ принимали равной единице и полагали $v_{\text {local }}=f$, где $f-$ условная частота, измеряемая в герцах $[7,11]$.

Спектральная кривая $W(f)$ имеет колоколообразную форму, ее максимум на частоте $f_{0}=0.41 \mathrm{~Hz}$ примерно совпадает с центром симметрии частотной области $f_{c}=0.4 \mathrm{~Hz}$. Площадь, ограниченная кривой $W(f)$, равна энергии спектра и в данном случае составляет $\sim 0.435 \mathrm{eV}$. Важным параметром спектра является показатель широкополосности $\mu$, значение которого находили по формуле $\mu=\Delta f / f_{0}$, где $\Delta f-$ ширина спектра, измеренная на его полувысоте. Здесь $\mu=1$. Поэтому спектр, изображенный на рис. $1, a$, обладает сверхширокополосными свойствами. Для узкополосных сигналов $\mu \ll 1$ [6-8]. Величина, обратная $\mu$, представляет собой добротность спектра $Q$. Центр тяжести спектра вычисляли по формуле [12,13]:

$$
M=\int_{0}^{\infty} W(f) f d f / \int_{0}^{\infty} W(f) d f .
$$

В работе исследованы характеристики бриллиантовэталонов ординарной окраски. Всего 15 экземпляров. По своим цветовым характеристикам подобранные образцы охватывают практически весь непрерывный цветовой ряд натуральных ограненных алмазов (бриллиантов). Установлено, что бриллианты с небольшим или незначительным оттенком имеют наибольшее значение добротности спектра $Q$ от $\sim 1.8$ до $\sim 3$. Такого сочетания параметров у других бриллиантов не обнаружено. Фантазийные бриллианты (12 экз.) имеют $Q \leq 1$. Низкая добротность пика характерна также для трех бриллиантов ординарных цветов (позиции Н, М, Р), которые образуют коричневый ряд $[10,14]$. По результатам исследований построены гистограммы распределения центра тяжести спектров по числу образцов в диапазоне частот (рис. 2, $a, b)$.

Частотную плоскость $W(f)$ (рис. $1, a)$ можно разделить на две части: левую и правую полуплоскости. Анализ гистограмм (рис. 2, $a, b)$ показывает, что в левой полуплоскости находятся спектры цветных бриллиантов (фантазийных) и ординарных бриллиантов так называемого коричневого ряда Н, М, Р [10] .

Правая полуплоскость состоит из спектров бесцветных и с небольшим оттенком бриллиантов. В области средней частоты выделяются два образца [10] со значениями М, равными 0.405 и $0.409 \mathrm{~Hz}$ соответственно. В дальнейшем примем обозначение спектров как спектры с левой, правой и средней характеристиками [14]. При этом бесцветные образцы находятся в правой, а цветные в левой полуплоскостях.

Таким образом, в свете люминесценции в частотной области можно выделить три группы бриллиантов, что значительно меньше числа характеристик бриллиантов по цвету [15-17].

Гистограммы распределения числа бриллиантов по величине показателя широкополосности $\mu$ представлены
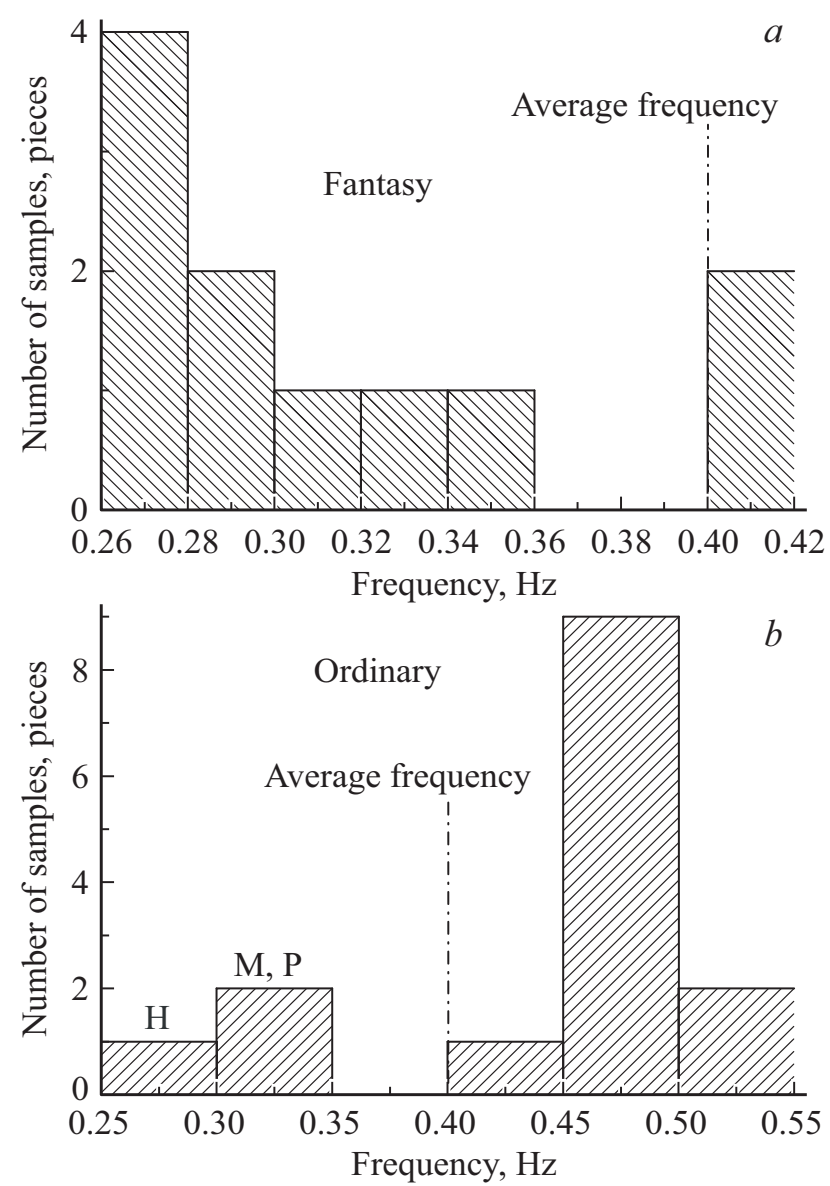

Рис. 2. Гистограммы, иллюстрирующие распределение центра тяжести спектров люминесценции фантазийных $(a)$ и ординарных $(b)$ бриллиантов по числу образцов в диапазоне частот. 

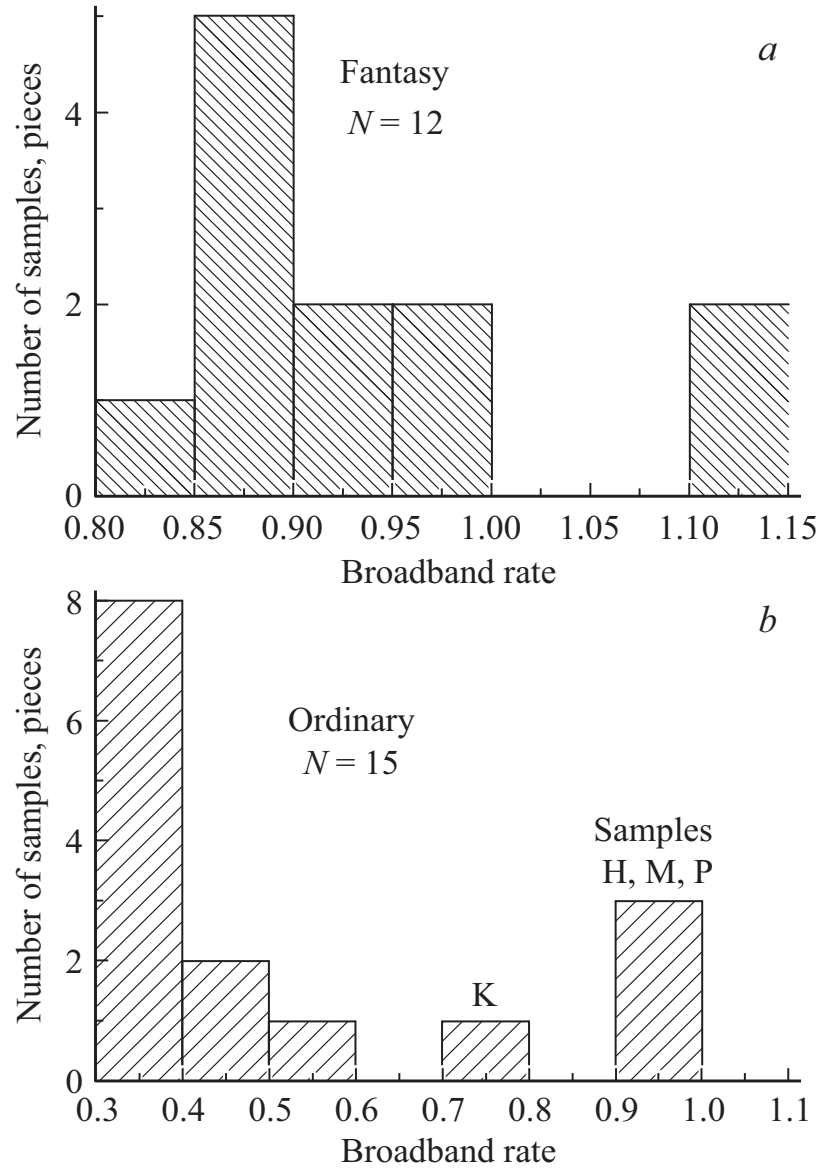

Рис. 3. Гистограмы распределения бриллиантов по величине показателя широкополосности.

на рис. 3. Можно заметить, что исследованные образцы бриллиантов обладают сверхширокополосными (СШП) свойствами $[6,18]$.

Фантазийные бриллианты имеют наибольшее значение $\mu \cong 0.8-1.1$. Среди ординарных бриллиантов три образца (Н, М, Р [10]) имеют значение $\mu$, характерное для фантазийных бриллиантов. Это согласуется с распределением бриллиантов по „центру тяжести“ спектров люминесценции (рис. 2). По величине показателя широкополосности можно выделить две группы бриллиантов: бесцветные или с оттенками разной насыщенности, у которых $\mu=0.3-0.8$, и цветные, где $\mu=0.8-1.1$. Образец К занимает промежуточное значение [10] (рис. 3).

Синтетические ограненные алмазы (7 экз.) имеют желто-зеленую и желто-коричневую цветовые гаммы. При возбуждении лазерным излучением на длине волны $\lambda \approx 532 \mathrm{~nm}$ люминесценция наблюдается у всех образцов бриллиантов, но интенсивность ее очень мала и по величине сравнима с уровнем помех $[10,14,16]$.

Установлено то, что 3 экз. из 7 образцов имеют спектры, которые по величине центра тяжести находятся в правой полуплоскости и своими цветовыми характеристиками отличаются от натуральных (бесцветных или небольшим оттенком алмазов) и могут быть исклю- чены из рассмотрения. Остальные образцы синтетических бриллиантов требуют дополнительного изучения их свойств.

Спектры люминесценции облагороженных алмазов (7 экз.) имеют повышенное значение показателя широкополосности, который изменяется от 0.73 до 1.5 . Центры тяжести спектров всех образцов располагаются в правой полуплоскости и по своим свойствам, также как и синтетические, отличаются от натуральных алмазов. Поэтому они могут быть исключены из рассмотрения.

\section{Определение характеристик алмазной среды по спектру люминесценции}

Для исследования свойств алмазной матрицы необходимо использовать импульсную переходную (временную) характеристику выходного сигнала (люминесценции) алмазной среды. По определению она представляет собой реакцию алмазной среды на входной сигнал в виде дельта-функции Дирака [19].

Для определения энергетических потерь в алмазной среде найдем комплексную импульсную характеристику люминесценции по формуле обратного преобразования Фурье [12]:

$$
g^{*}(t)=\int_{-\infty}^{\infty} G(f) \exp (-2 \pi j f t) d f
$$

где $G(f)$ - дифференциальная функция распределения спектра люминесценции.

Функция $G(f)$ нормирована по площади на единицу, т. е. выполняется условие нормировки

$$
\int_{-\infty}^{\infty} G(f) d f=1
$$

По экспериментальному спектру, изображенному на рис. 1, $a$, численным методом с помощью математического пакета Origin получено решение уравнения (2). Данные расчета представлены на рис. 4.

Импульсная характеристика монотонно спадает во времени. Длительность спада, измеренная на ее полувысоте, составляет $\sim 2.2 \mathrm{fs}$, т. е. находится в фемтосекундном временном диапазоне.

Особенностью кривой $g(t)$ является наличие у нее в начале координат относительно плоского участка. Это позволяет представить исходный импульс света в упрощенном виде. Он состоит из прямоугольника „оabc“ и треугольника „сbd“. Сторона треугольника „bd“ является касательной к кривой $g(t)$ на уровне 0.5. Таким образом, временной процесс люминесценции в первом приближении можно представить в виде прямоугольного и следующим за ним во времени треугольного импульса. 


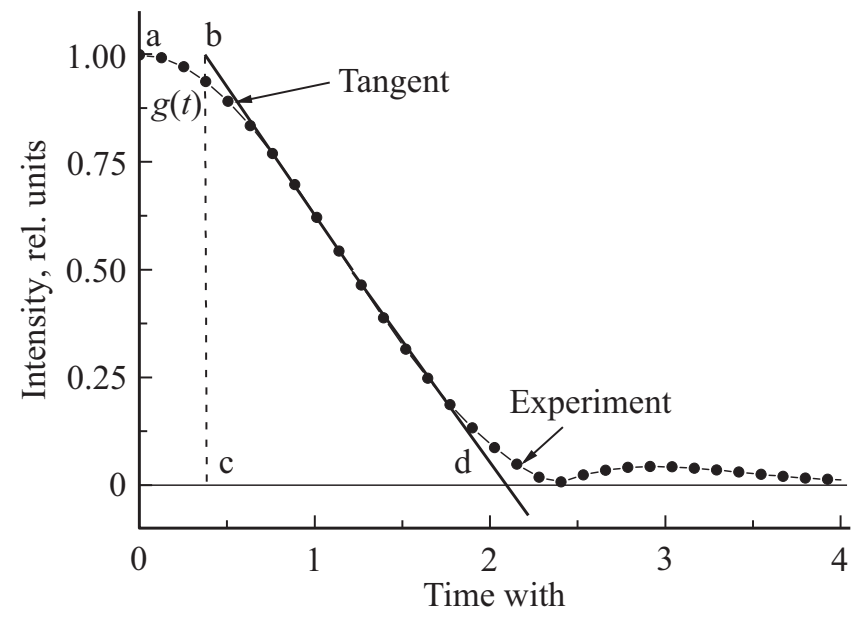

Рис. 4. Импульсная характеристика спектра люминесценции бриллианта природного происхождения (его данные указаны в подписи к рис. 1).

Комплексную частотную характеристику люминесценции находим по формуле прямого преобразования Фурье [12]:

$$
W^{*}(f)=\int_{-\infty}^{\infty} g(t) \exp (j 2 \pi f t) d t
$$

где $g(t)$ - модуль комплексной импульсной характеристики люминесценции.

Функция $W^{*}(f)$ содержит вещественную и мнимую части [19]:

$$
\begin{gathered}
W^{*}(f)=A(f)+j B(f), \\
A(f)=\operatorname{Re} W^{*}(f), \\
B(f)=\operatorname{Im} W^{*}(f) .
\end{gathered}
$$

Модуль

$$
W(f)=\sqrt{ }\left(A^{2}(f)+B^{2}(f)\right) .
$$

Фазовый угол

$$
\varphi=\operatorname{arctg} \frac{B(f)}{A(f)}
$$

Результаты численного решения уравнений (3)-(8) для импульсной характеристики фантазийного бриллианта (рис. 4) представлены в виде графических зависимостей на рис. $5, a-d$. Вещественная $A(f)$ и мнимая $B(f)$ части и модуль $W(f)$ комплексной частотной характеристики (кривые 1,2 и 3 соответственно) представлены на рис. 5, $a$. В точке „а“ вещественная часть $A(f)$ равна нулю. Частота сигнала, при которой это имеет место, называют частотой релаксации $f_{p}$. В то же время мнимая часть на этой частоте $B\left(f_{p}\right)$ сохраняет конечное значение. Ее можно определить из графической зависимости амплитудной фазовой частотной характеристики, изображенной на комплексной плоскости (рис. 5, $b$ ) по точке пересечения годографа с осью ординат. Аналитическим путем величину $B\left(f_{p}\right)$ можно найти из (3), полагая в нем $g(t)=g(0)=1$,

$$
B\left(f_{p}\right)=-j / 2 \pi f_{p} .
$$

В данном случае $f_{p}=0.44 \mathrm{~Hz}$, поэтому $B\left(f_{p}\right) \approx$ $\approx 0.36 \mathrm{~s}$, что хорошо согласуется с данными, полученными из графика рис. $4(\approx 0.32 \mathrm{~s})$.

Для объяснения полученных результатов используем фазовый спектр, который позволяет учесть влияние угла диэлектрических потерь $\delta$ на величину фазового сдвига $\varphi$. График фазового спектра приведен на рис. 5, $d$. Здесь же в правом верхнем углу приведена зависимость тангенса угла диэлектрических потерь $\operatorname{tg} \delta$ от частоты. Величину тангенса находили по формуле

$$
\operatorname{tg} \delta=A(f) / B(f) .
$$

Из графика рис. $5, d$ видно, что угол $\varphi$ зависит от частоты. Он достигает максимального значения, равного $\varphi_{\max }$, а затем падает по величине. Физически это явление можно объяснить влиянием угла $\delta$. Углы $\varphi$ и $\delta$ связаны между собой соотношением $\delta-\varphi=-90^{\circ}[20,21]$. Расчетно-экспериментальный график зависимости $\operatorname{tg} \delta$ от частоты представлен на вставке рис. $5, d$. Тангенс $\operatorname{tg} \delta$ при $f \approx 0$ равен $\sim-11$, а при $f=f_{p}$ принимает значение 0.017 , что соответствует $\sim-0.95^{\circ}$. Когда $f>f_{p}$, то $\operatorname{tg} \delta$ возрастает по величине, что приводит к уменьшению угла $\varphi$.

Однако для анализа фазового спектра удобнее использовать понятие группового времени задержки (ГВ3), В общем случае ГВЗ определяется первой производной фазового спектра со знаком минус [22]:

$$
\tau(f)=-\frac{1}{360} \frac{d \varphi}{d f},
$$

где $\varphi$ измеряется в угловых градусах.

Дифференцирование кривой $\varphi(f)$ дает величину ГВЗ в зависимости от частоты (рис. 5, c). ГВ3 имеет наибольшую величину $\tau_{0}=0.94 \mathrm{~s}$ при $f \approx 0$ и $\tau\left(f_{p}\right)=0$, когда $f=f_{p}$. Время $\tau_{0}$ определяет время задержки в области нижних частот. Понятие ГВЗ имеет смысл только для положительных значений, следовательно, в диапазоне частот $f_{p} \leq f \leq f_{m}$ ГВЗ равно нулю. Это означает, что кристаллическая решетка алмаза не реагирует на электромагнитное излучение, которое распространяется со скоростью, равной скорости в вакууме. Такой режим работы кристалла называют диэлектрической или максвелловской релаксацией $[23,24]$. В такой ситуации рекомбинация и диффузия заряженных носителей заряда в кристалле алмаза отсутствуют, показатель преломления равен единице. Время максвелловской релаксации [20]

$$
\tau_{m}=1 / 2 \pi f_{p} .
$$

Таким образом, условно можно выделить две частотные области: участок АВ (рис. 5,a), в котором 

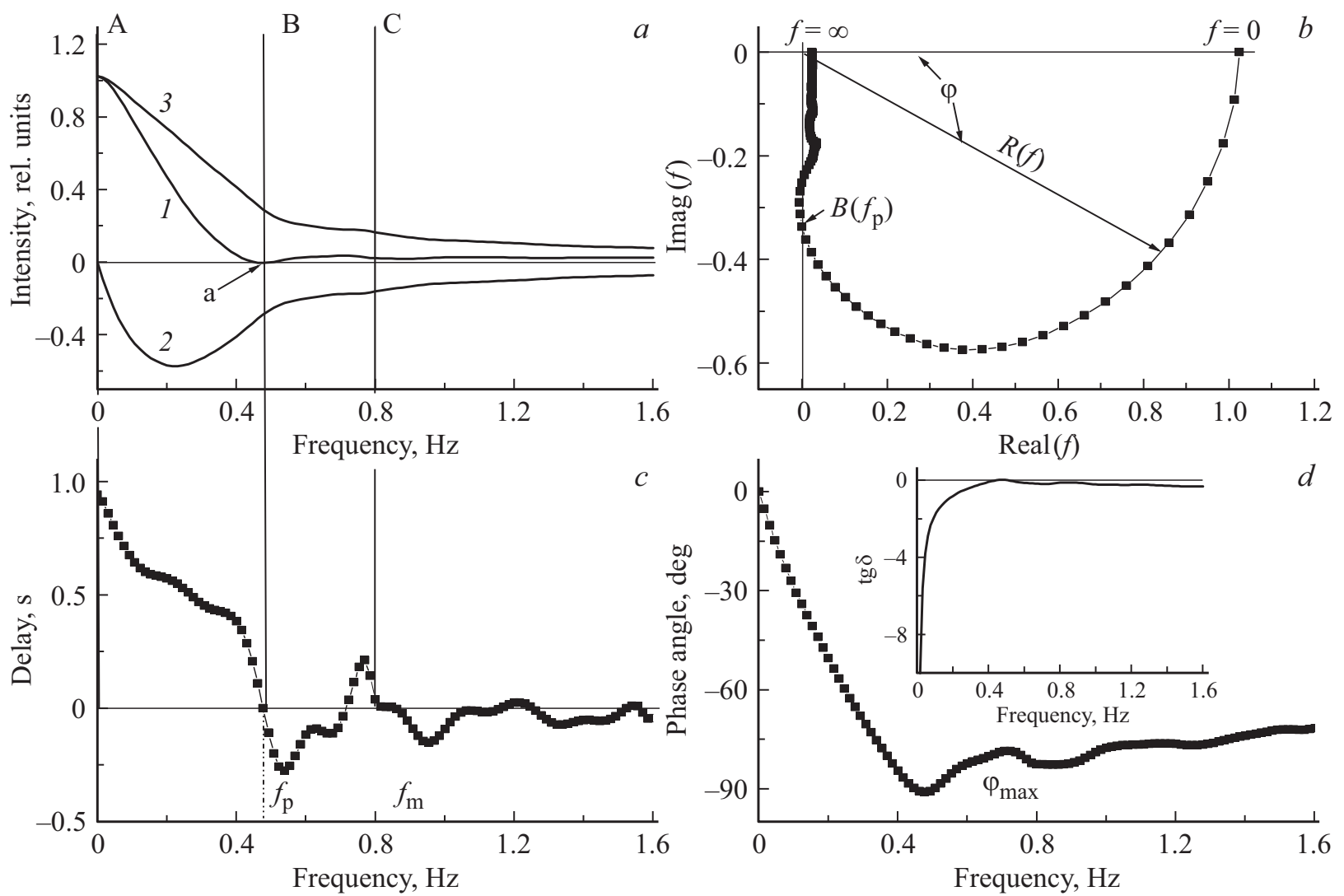

Рис. 5. Кривые комплексной частотной характеристики люминесценции фантазийного бриллианта $D$ : $(a)$ вещественная $(1)$, мнимая (2) и модуль (3); (b) амплитудная фазово-частотная характеристика; $(c)$ зависимость группового времени задержки от частоты; $(d)$ фазовый спектр. Области частоты: $\mathrm{AB}$ - режим омической и $\mathrm{BC}-$ режим диэлектрической релаксации.

Основные параметры частоты релаксации

\begin{tabular}{l|c|c|c|c|c}
\hline $\begin{array}{c}\text { Тип } \\
\text { бриллианта }\end{array}$ & $\begin{array}{c}\text { Среднее } \\
\text { значение, } \mathrm{Hz}\end{array}$ & $\begin{array}{c}\text { Среднее квадратичное } \\
\text { отклонение, } \mathrm{Hz}\end{array}$ & $\begin{array}{c}\text { Минимум, } \\
\mathrm{Hz}\end{array}$ & $\begin{array}{c}\text { Максимум, } \\
\mathrm{Hz}\end{array}$ & $\begin{array}{c}\text { Количество } \\
\text { образцов }\end{array}$ \\
\hline Ординарный & 0.474 & 0.013 & 0.36 & 0.58 & \\
Фантазийный & 0.408 & 0.009 & 0.35 & 0.47 & 15 \\
Синтетический & 0.595 & 0.053 & 0.28 & 0.67 & 7 \\
Облагороженный & 0.578 & 0.009 & 0.56 & 0.63 & 7
\end{tabular}

реализуется режим омической релаксации, т.е. выполняется условие электрической нейтральности среды. Во временной области (рис. 4) ему соответствует участок импульсной характеристики, расположенный в правой части относительно горизонтальной полочки ,арас.

На другом участке ВС выполняется режим диэлектрической релаксации. Здесь атомы кристалла алмаза находятся как бы в ,замороженном“ состоянии, электронфононное взаимодействие отсутствуют. Во временной области (рис. 4) этому режиму соответствует прямоугольный импульс „оарс“ с шириной, равной $\sim 0.36 \mathrm{~s}$. Расчет по формуле (12) дает время $\tau_{m}=0.4 \mathrm{~s}$. Результаты расчета и аппроксимации хорошо согласуются между собой.
С учетом постоянной Планка $h=4.1 \cdot 10^{-15} \mathrm{eV} \cdot \mathrm{s}$ peальное значение $\tau_{m} \approx 10^{-15} \mathrm{~s}=1 \mathrm{fs}$, частота релаксации $f_{p} \approx 0.1 \cdot 10^{15} \mathrm{~Hz}=100 \mathrm{THz}$.

Кривая импульсной характеристики, изображенная на рис. 4 по существу представляют релаксацию люминесценции во времени. В начальные моменты времени интенсивность излучения на отрезке „аb“ сохраняет постоянное значение. Здесь имеет место резонансное излучение, которое представляет собой частный и наиболее простой случай фотолюминесценции без энергетических потерь. Ранее резонансное излучение наблюдали в основном в газообразных средах при низком давлении и комнатной температуре [25,26].

Гистограмма распределения частоты релаксации ограненных алмазов по числу образцов бриллиантов раз- 


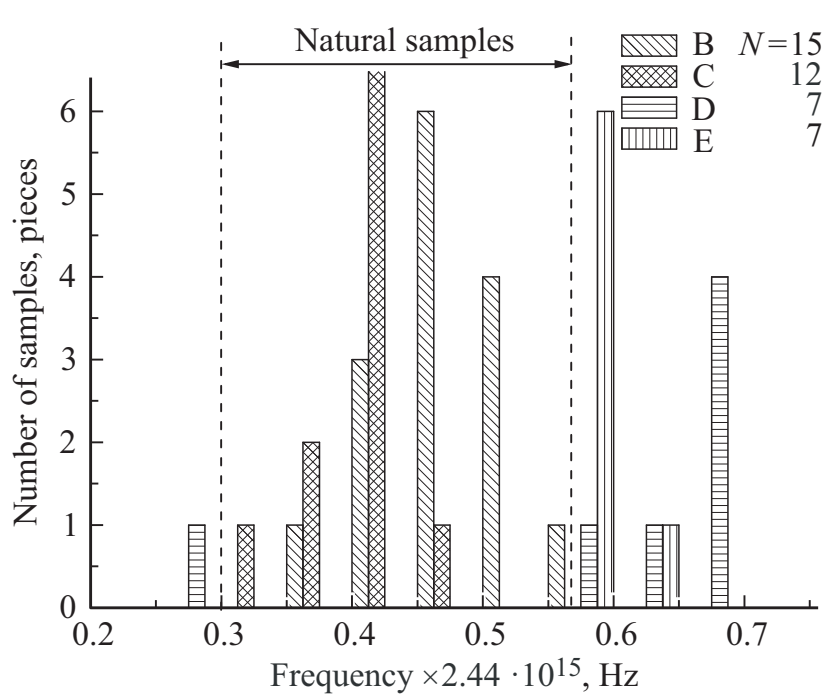

Рис. 6. Гистограмма распределения частоты релаксации ограненных алмазов по числу образцов бриллиантов различного происхождения: В - ординарные, C - фантазийные, D синтетические, Е - облагороженные.

личного происхождения, полученная на основе нашего исследования образцов, приведена на рис. 6. Данные по частоте релаксации исследуемых камней приведены в таблице.

Из данных таблицы можно видеть, что среднее значение частоты релаксации у природных образцов меньше частоты релаксации алмазов искусственного происхождения. Природные алмазы имеют разброс частоты от образца к образцу (27 экз.) в диапазоне $0.35-0.58 \mathrm{~Hz}$. У облагороженных (7 экз.) и синтетических (7 экз.) этот разброс составляет $0.59-0.67 \mathrm{~Hz}$, и только один (синтетический) образец имеет заметное отличие от других, частота $f_{p}=0.28 \mathrm{~Hz}$.

Таким образом, по частоте $f_{p}$ природные образцы заметно отличаются от синтетических и облагороженных алмазов.

Частота $f_{p}$ однозначно связана с потерями энергии в алмазной среде. Это непосредственно следует из

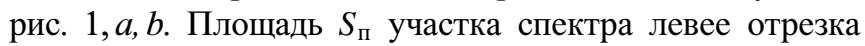
прямой В определяет долю потери энергии люминесценции, связанную с электрон-фононным взаимодействием в кристаллической решетке. Площадь $S_{p}$ правее отрезка прямой линии В определяет энергию резонансного излучения. Относительная величина потерь энергии $\gamma$ в спектре люминесценции находится как $\gamma=S_{\text {п }} / S$, где $S=S_{\text {п }}+S_{p}$. В нашем случае $S_{\text {п }}=0.24 \mathrm{eV}$ и $S=0.435 \mathrm{eV}$, следовательно, коэффициент потерь люминесценции $\gamma \cong 0.55$.

Из исследованных бриллиантов ординарные образцы (прозрачные и с небольшим оттенком цвета) имеют наименьшие потери энергии, коэффициент $\gamma \cong 0.3-0.45$. Другие бриллианты имеют $\gamma \cong 0.6-0.98$. Следовательно, резонансная люминесценция наиболее полно выражена в бесцветных бриллиантах.

\section{Заключение}

Таким образом, в области спектральных частот можно выделить три группы природных алмазов. В левой части - находятся цветные, в правой - бесцветные или с небольшим оттенком и в средней - бриллианты с желтым оттенком.

Бриллианты с небольшим или незначительным оттенком имеют наибольшее значение добротности спектра $Q$ от $\sim 1.8$ до $\sim 3$. Такого сочетания параметров у других бриллиантов не обнаружено.

Спектры люминесценции алмазов обладают СШПсвойствами: ординарные имеют показатель $\mu=0.3-0.5$, фантазийные имеют большее значение $\mu=0.8-1.1$, что связано с более сильным электрон-фононным взаимодействием.

Спектры синтетических бриллиантов (3 экз. из 7 образцов) по величине центра тяжести находятся в правой частотной полуплоскости и по своим цветовым характеристикам отличаются от натуральных образцов и могут быть исключены из рассмотрения. Такие же свойства проявляют все 7 экз. облагороженных бриллиантов.

Условно можно выделить две частотные области, в которых реализуется режимы омической и диэлектрической релаксации. В первом случае среда проявляет активные, в другом случае - инертные свойства, где люминесценция проявляет свойства резонансного излучения.

Природные алмазы по частоте релаксации заметно отличаются от синтетических и облагороженных образцов, что является характерным признаком их отличия.

Наименьшие значения потерь энергии имеют бесцветные или с небольшим оттенком ординарные алмазы.

\section{Конфликт интересов}

Авторы заявляют, что у них нет конфликта интересов.

\section{Список литературы}

[1] Titkov S.V., Shigley C.M., Breeding J.E., Mineeva R.M., Zudin N.G., Sergeev A.M. // Gems \& Gemology. 2008. V. 44. N 1. P. 56.

[2] Shigley J.E., McClure C.M., Breeding S.F., Shen A.H., Muhlmeister S.M. // Gems \& Gemology. 2004. V. 40. N 2. P. 128

[3] HORIBA Jobin Yvon Raman Application Note. Raman Diffusion and Photoluminescence Analysis for Coloured Diamond Investigation. 2006.

[4] Природные алмазы России. Научно-справочное изд. / Под ред. Кваскова В.Б. М.: Полярон, 1977. 204 с.

[5] Алмаз в электронной технике. Отв. редактор Квасков В.Б. М.: Энергоатомиздат, 1990. 248 с.

[6] Лазоренко О.В., Черногор Л.В. // Радиофизика и радиоастрономия. 2008. Т. 13. № 2. С. 166.

[7] Зиенко С.И., Беляков М.В., Малышкин В.В. // Наукоемкие технологии. 2017. Т. 18. № 8. С. 40. 
[8] Зиенко С.И., Слабковский Д.С. // Естественные и технические науки. 2014. № 9-10. С. 202.

[9] Акустооптический спектрометр НТЦ УП РАН, версия 01.03.2003.

[10] Зиенко С.И, Слабковский Д.С. // Вестник МЭИ. 2015. № 5. С. 90.

[11] Зиенко С.И., Слабковский Д.С. // Естественные и технические науки. 2014. № 9-10. С. 195.

[12] Гоноровский И.С. Радиотехнические цепи и сигналы. М.: Радио и связь, 1986. 592 с.

[13] Френкс Л. Теория сигналов / Под ред. Д.Е. Вакмана. М.: Сов. радио, 1974.

[14] Зиенко С.И. // Успехи прикладной физики. 2018. Т. 6. № 4. C. 297.

[15] Бочаров А.М., Нюбин В.В., Муконин А.А., Слабковский Д.С. Фантазийные цвета бриллиантов. Смоленск, 2011. $141 \mathrm{c}$

[16] Бочаров А.М., Нюбин В.В. Колорометрия бриллиантов / Под ред. С.И. Зиенко. Смоленск, 2008. 188 с.

[17] Слабковский Д.С. Бриллианты: классификация, стандарты качества. Навигатор ювелирной торговли. М.: ООО „Ювелирный дом „Россия“, 2015. 152 с.

[18] Зиенко С.И., Беляков М.В., Малышкин В.В. // Наукоемкие технологии, 2017. Т. 18. № 8. С. 40.

[19] Зельдович Я.Б., Мышкис А.Л. Элементы прикладной математики. М.: Наука, 1972. 512 с.

[20] Пасынков В.В. Материалы электронной техники. М.: Высшая школа, 1980. $406 \mathrm{c}$.

[21] Мирдель Г. Электрофизика. М.: Мир, 1972. 608 с.

[22] Баскаков С.И. Радиотехнические цепи и сигналы. М.: Высшая школа, 2000. 462 с.

[23] Шалимова К.В. Физика полупроводников. М.: Энергия, 1971. $312 \mathrm{c}$

[24] Зиенко С.И. // Радиотехника. 1989. № 9. С. 24.

[25] Уэйн Р. Основы и применение фотохимии. М.: Мир, 1991. $304 \mathrm{c}$.

[26] Физика и химия твердого состояния / Под ред. В.С. Постникова. М.: Металлургия, 1978. 544 с. 